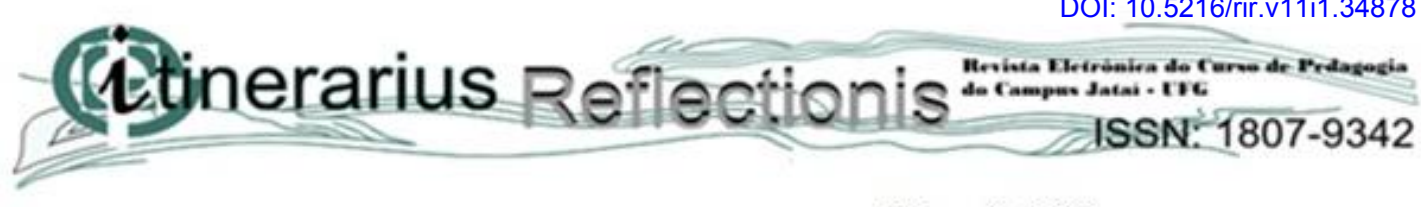

v.11, n. 1,2015

\title{
PROFESSOR NA EDUCAÇÃO INFANTIL: SER OU NÃO SER? E COMO SER? EIS A QUESTÃO...
}

\author{
Sílvia Adriana Rodrigues ${ }^{1}$
}

\section{RESUMO}

Este texto se configura em substrato da pesquisa em andamento no âmbito do Grupo de Pesquisa: Profissão Docente, Formação, Identidade e Representações Sociais - GPDFIRS FCT/UNESP, com o objetivo de identificar e analisar de forma comparativa o desenvolvimento da aprendizagem profissional da docência, nos cursos oferecidos por distintas instituições de ensino superior. A investigação adota caráter qualitativo e se desenvolve de modo longitudinal, uma vez que tem a pretensão de acompanhar estudantes em todo seu processo de formação inicial. Nessa direção, serão trazidos e discutidos os dados referentes a dois momentos da pesquisa, obtidos a partir do uso de questionário misto nos anos letivos de 2011 e 2013. Dentro dos limites deste texto, a discussão apresentada será pautada nas respostas oferecidas às questões dos referidos questionários, ou seja, as que solicitavam aos estudantes que discorressem sobre o que é ser professor (de modo geral, no ano de 2011) e o que é ser professor da Educação Infantil (de forma específica, em 2013). A análise dos dados levou a uma conclusão provisória paradoxal; se, por um lado, os dados indicam a possibilidade de os cursos de formação inicial provocarem mudanças na percepção do que é ser professor da Educação Infantil, por outro, notou-se que ainda há no imaginário social uma confusão da docência com papéis domésticos ou confessionais, antes da entrada no curso, e permanência de uma visão romantizada e marcada pelo ideário do senso comum, mesmo após o ingresso no curso.

Palavras-chave: Educação Infantil. Profissão professor. Formação inicial.

\section{TEACHER IN EARLY CHILDHOOD EDUCATION: BE OR NOT TO BE? AND HOW TO BE? THAT IS THE QUESTION...}

\begin{abstract}
This text is configured in search substrate in progress under the Research Group: Teaching Profession, Education, Identity and Social Representations - GPDFIRS - FCT/UNESP, in order to identify and analyze comparative way the development of professional learning teaching in courses offered by different institutions of higher education. The research adopts qualitative and develops longitudinally as it pretends to follow students throughout
\end{abstract}

\footnotetext{
${ }^{1}$ Mestre em Educação. Professora Assistente da Universidade Federal do Mato Grosso do Sul - Campus do Pantanal (UFMS/CPAN). E-mail: silvia.rodrigues@ufms.br.
} 


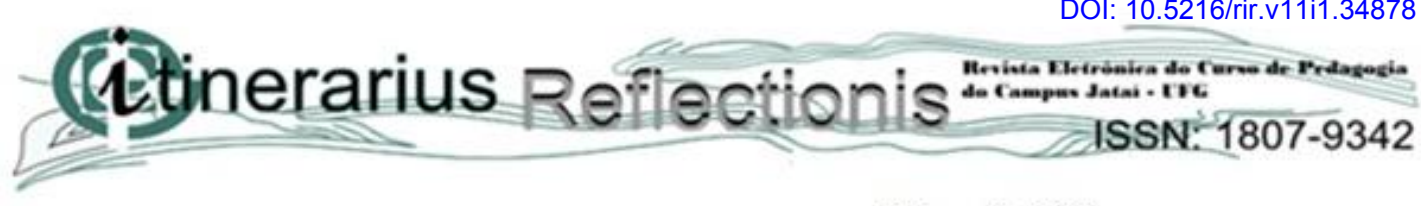

v.11, n. 1,2015

their initial training process. In this sense, the data for two moments of the research will be brought and discussed, obtained from the use of mixed questionnaire in the school years 2011 and 2013. Within the limits of this paper, the discussion will be presented guided the answers provided to the questions of those questionnaires, ie requesting to students who would discourse on what is to be teacher (generally in 2011) and what being a professor of early childhood education (specifically in 2013). Data analysis led to a paradoxical provisional conclusion; on the one hand, the data indicate the possibility of the initial training courses cause changes in the perception of being a teacher of early childhood education, on the other, it was noted that there is still the social imaginary one of teaching confusion with domestic roles or confessional, before entering the course, and length of a romanticized vision and marked by common sense ideas even after enrolling in the course.

Keywords: Childhood Education. Job teacher. Initial training.

\section{INTRODUÇÃO}

Ninguém começa a ser educador numa certa terça-feira
às quatro horas da tarde. Ninguém nasce educador
ou marcado para ser educador. A gente se faz educador,
a gente se forma, como educador, permanentemente,
na prática e na reflexão sobre a prática.

(Paulo Freire) $)^{2}$

A epígrafe trazida para iniciar as provocações contidas neste texto foi selecionada não somente por sua obviedade, acerca da afirmação de que a profissão docente se constrói no dia a dia do seu exercício, na tão propalada práxis, mas também porque ela sugere pensar sobre o que está por trás dessa construção, sobre o que mobiliza os sujeitos a escolherem, bem como sobre o que estes pensam, quando a escolhem; impele ainda à reflexão sobre que percepção os sujeitos em processo de formação têm a respeito da profissão que, em tese, exercerão num futuro próximo.

Esta é uma das questões que mobilizaram a elaboração e a consecução da pesquisa em andamento, desde o ano de 2011, no âmbito do Grupo de Pesquisa "Profissão Docente, Formação, Identidade e Representações Sociais - GPDFIRS", da Faculdade de Ciências e Tecnologia - Campus UNESP de Presidente Prudente (FCT/UNESP), a qual adotou como

\footnotetext{
${ }^{2}$ FREIRE, P. A educação na cidade. São Paulo: Cortez, 1991.
} 


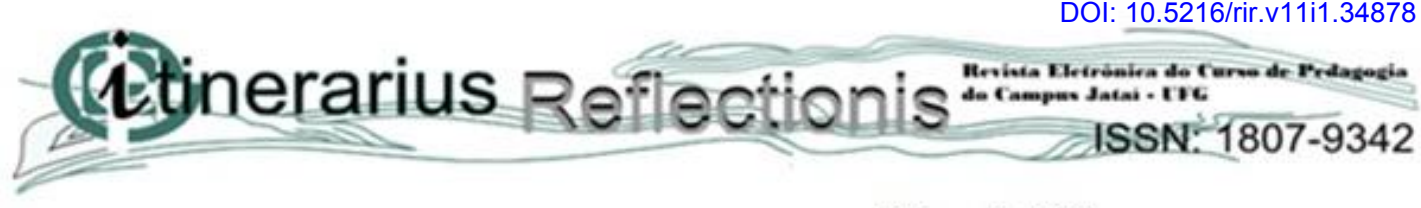

$$
\text { v.11, n. } 1,2015
$$

objetivo geral identificar e analisar, de maneira comparativa, o desenvolvimento da aprendizagem profissional da docência nos cursos oferecidos por distintas instituições públicas de ensino superior. Dessa forma, nos limites deste texto, o que apresentarei é um pequeno substrato desse estudo, mais especificamente, discutirei a percepção de estudantes em processo de formação inicial, matriculados em cursos de Pedagogia, sobre ser professor e ainda ser professor na/da Educação Infantil.

Nesse intento, trago inicialmente uma breve contextualização do cenário da Educação Infantil, no Brasil, e algumas questões referentes à formação de professores para atuar nesse nível de ensino, de sorte a, em seguida, apresentar e discutir os dados relativos a dois momentos da pesquisa, obtidos a partir do uso de questionário misto, nos anos letivos de 2011 e 2013, encerrando com algumas considerações pertinentes.

\section{A EDUCAÇÃO INFANTIL E SUAS PROFISSIONAIS ${ }^{3}$ NO CONTEXTO BRASILEIRO}

A Educação Infantil no Brasil e a formação de suas professoras ganharam destaque no cenário brasileiro com a promulgação da Constituição Federal de 1988, a qual prevê a educação em creche em pré-escolas como um dos direitos inalienáveis a ser oferecido pelo Estado a todas as crianças, sem distinção (BRASIL, 1988). É a partir desse marco que creches e pré-escolas começaram a construir uma nova identidade, até então marcada por discrepâncias determinadas pela classe social das crianças atendidas.

De acordo com Paschoal e Machado (2009), por essa lei, as creches, anteriormente vinculadas à área da assistência social, passaram a ser de responsabilidade da educação. Tomou-se por orientação o princípio de que essas instituições não devem apenas cuidar das crianças, no sentido restrito da palavra, mas devem, prioritariamente, desenvolver um trabalho de cunho educacional. Dessa forma, é possível afirmar que se instala entre os diferentes sujeitos envolvidos com a Educação Infantil uma comoção reflexiva acerca dos

\footnotetext{
${ }^{3}$ Neste texto, usarei o gênero feminino, tendo em vista a grande maioria de mulheres atuando na profissão docente e ainda a quase exclusividade da presença delas na Educação Infantil.
} 


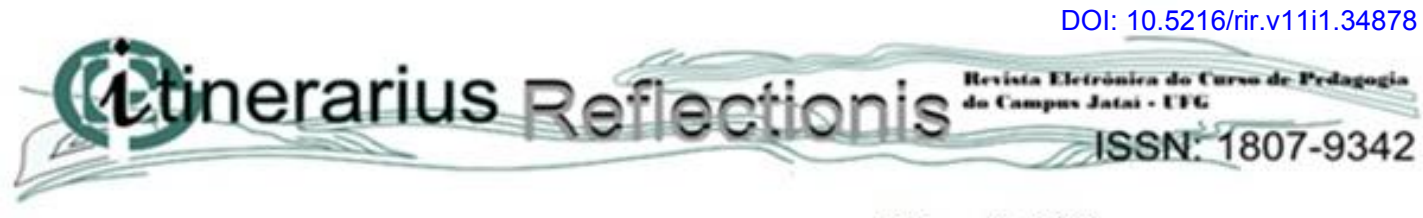

$$
\text { v.11, n. } 1,2015
$$

novos rumos que as instituições de Educação Infantil deveriam tomar, no que se refere a garantir a efetivação da lógica a ser instalada em sua prática, quer dizer, "cuidar educando e educar cuidando".

Um novo avanço significativo, em termos legais, é alcançado com a aprovação da Lei de Diretrizes e Bases da Educação - LDB, nº 9.394, no ano de 1996, a qual estabelece a Educação Infantil como primeira etapa da educação básica. Com a LDB, há ainda a definição de que serão docentes o(a)s profissionais que devem atuar junto às crianças, nesse nível de ensino, garantindo assim uma certa especificidade na formação profissional. Temse, igualmente, com a aprovação das novas Diretrizes Curriculares Nacionais dos Cursos de Pedagogia (BRASIL, 2006), o reconhecimento do legítimo espaço de formação de professore(a)s para/da Educação Infantil, exigindo a oferta de conteúdos teóricos específicos e estágio curricular em creches e pré-escolas. Leite Filho (2005, p. 1) aponta que, dentro da nova perspectiva posta,

[...] o papel do educador deixa de ter puramente a dimensão do cuidado, assumindo conotações de intencionalidade pedagógica, ampliando o seu papel no que refere à dimensão do educar. [...] Portanto, os processos de formação deverão contribuir não somente para a aquisição de conhecimentos sobre a infância e as atividades pedagógicas, mas também, para o desenvolvimento da sensibilidade do educador e do compromisso com a transformação da realidade educacional.

O mesmo autor ainda enfatiza que não há como negar que, nas últimas décadas do século XX, houve um grande avanço no sentido de assegurar legalmente a criança como sujeito de direitos e o estabelecimento de normas e diretrizes que estavam, no texto e em seu espírito, assegurados direitos para a infância (LEITE FILHO, 2005).

No entanto, é preciso ter clareza que garantir os direitos legais não é sinônimo de têlos efetivados... Para tanto, é necessário que o avanço legal conquistado acompanhe, para além da defesa deles, ações que venham a torná-los de fato realidade.

Acompanhando os avanços legais, Rocha (1999) analisou a produção de pesquisas em Educação Infantil, no Brasil, identificando uma acumulação de conhecimentos sobre Educação Infantil com origem em diferentes campos científicos, os quais resultaram em 


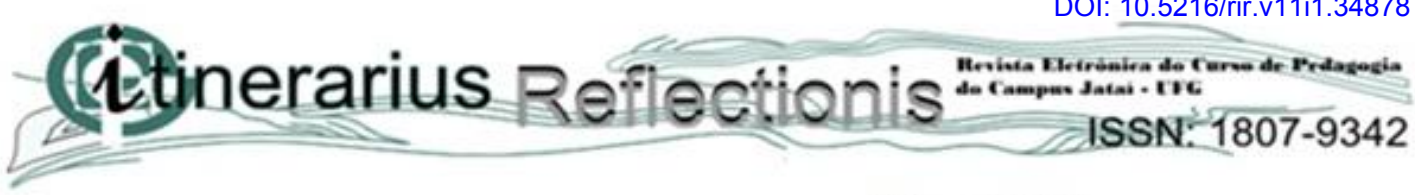

v.11, n. 1,2015

contribuições para a constituição de um campo particular, denominado pela autora Pedagogia da Educação Infantil, e a difusão no discurso pedagógico da necessidade de se construir essa pedagogia.

Passado um razoável período de tempo desde todos esses avanços, pergunta-se, por conseguinte, onde encontrar (ou procurar) a resposta para a situação posta, a de como transformar em realidade todas as conquistas legais das décadas passadas. Uma das hipóteses que vem sendo perseguida é a de que uma valiosa chave para essa questão seria o investimento de diversas naturezas na formação inicial (não excetuando a continuada) das profissionais, para atuar junto às crianças em creches e pré-escolas.

Discutir a formação de professoras de criança pequenas é oportuno, tendo em vista a crença e a necessidade de a Educação Infantil ter uma proposta educacional diferenciada do Ensino Fundamental e, portanto, que requer das profissionais conhecimento/saberes que contemplem as especificidades dos sujeitos a quem dirigem suas ações. A atuação na Educação Infantil é diferente da docência no Ensino Fundamental, e isso precisa ser explicitado de forma contundente, no momento da formação, para que as especificidades do trabalho docente com as crianças pequenas, em creches e pré-escolas, sejam respeitadas e principalmente garantidas.

Nessa direção, é consenso entre os que se propõem discutir a questão da formação das profissionais para atuarem na Educação Infantil a necessidade de se pensar/defender uma identidade profissional específica; pois, como apontam Silveira e Freire (2013), diferentemente do Ensino Fundamental, o papel da professora adquire outros contornos, pois é ele quem cria, mas também recria os espaços; disponibiliza materiais; promove, mas também participa das brincadeiras e das músicas, ou seja, faz a mediação da construção do conhecimento pela criança de maneira totalmente diferenciada.

De acordo com Santos e Furtado (2013, p. 7), a formação profissional das professoras da/para a Educação Infantil precisa ser constituída de uma complexidade de saberes, sendo necessário, por conseguinte, investir na sua formação para lidar com as crianças, porque é fundamental "que o/a docente tenha consciência de seu papel enquanto 


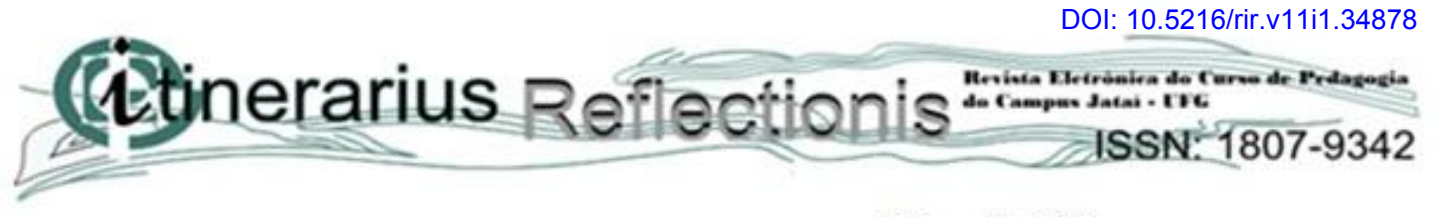

$$
\text { v.11, n. } 1,2015
$$

profissional na Educação Infantil, tendo como base as especificidades das crianças pequenas e a diversidade que permeia essa etapa da educação".

Ostetto (1997, p. 13) já perguntava:

[...] quem é o profissional de educação infantil? Pajem, babá, atendente, monitor, recreacionista, auxiliar de desenvolvimento infantil, professor, outra coisa... Quem é? Este questionamento, que chamei de crucial, não se refere somente a uma denominação, mas diz respeito ao perfil de um profissional que, por muito tempo, esteve "misturado" na própria "indefinição" do seu campo de atuação: casa, escola, nem isto, nem aquilo... (grifos no original).

Assim, a atuação profissional, no âmbito da Educação Infantil, precisa de intencionalidade, também carregada de especificidade, uma vez que é necessário ao profissional que atua diretamente com a criança, no desempenho de sua função, aproximação, mas, igualmente, distanciamento do cuidar materno familiar. Em outros termos, ao mesmo tempo em que esse profissional se aproxima do papel de "mãe", ao articular as dimensões de cuidado e de educação, tão necessárias nessa etapa da vida da criança, deve distanciar-se dele, oferecendo atenção de cunho profissional. Esse exercício de aproximação e distanciamento deve ser uma constante na prática da Educação Infantil e elemento básico na construção da identidade de seus profissionais, porque, ao integrar outros papéis, se encontra envolto em inúmeras complexidades (RODRIGUES, 2008, 2013).

Ainda nessa linha de pensamento, Gomes (2009) salienta que, além da congregação de saberes e fazeres, é preciso desenvolver a habilidade de reflexão diária, para, assim, atuar de modo consciente nesse nível de ensino. Em suas palavras:

Ser professor requer saberes e conhecimentos científicos, pedagógicos, educacionais, sensibilidade, indagação teórica e criatividade para encarar as situações ambíguas, incertas, conflituosas, e por vezes, violentas, presentes nos contextos escolares e não escolares. É da natureza da atividade docente proceder à mediação reflexiva e crítica entre transformações sociais concretas e a formação humana dos alunos, questionando o modo de pensar, sentir, agir e de produzir e compartilhar conhecimentos. (p. 15). 


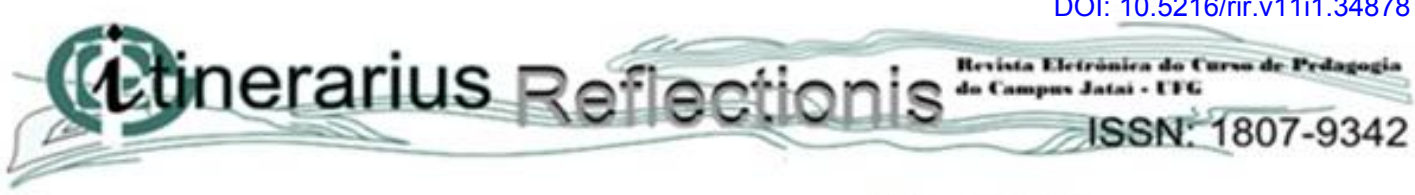

v.11, n. 1,2015

A mesma autora ressalta que o processo de formação para atuação na Educação Infantil deve ser permanente e envolver, em sua dinâmica, a valorização da identidade e do profissionalismo dos professores, tornando-se uma complexa tarefa de aprimoramento da qualidade cotidiana do trabalho. O processo de valorização pressupõe a formação identitária contínua, a qual reconhece a docência como um campo que abarca conhecimentos específicos configurados em quatro conjuntos: o primeiro relacionado aos conteúdos das diversas áreas do saber e do ensino; o segundo, aos conteúdos didáticopedagógicos; o terceiro são conteúdos ligados a saberes pedagógicos mais amplos do campo teórico da prática educacional; o quarto, associado à explicitação do sentido da existência humana e a sensibilidade pessoal e social (GOMES, 2009).

É importante dar especial destaque à questão da valorização e do profissionalismo, uma vez que, na atualidade, a profissão docente sofre de certo desprestígio, devido a diferentes variáveis (más condições materiais de trabalho, baixos salários etc.), a questão ainda mais problemática, no que diz respeito à atuação profissional no âmbito da Educação Infantil.

A profissão docente, assim como outras profissões, é marcada pelo discurso social que identifica e define papéis aos quais aqueles que se destinam a exercer determinada profissão devem se ajustar. No emaranhado dos discursos ao longo da história, convivem e revezam-se imagens de diferentes grupos sociais, como o dos próprios professores sobre si mesmos, dos órgãos que regulamentam a profissão e das instituições formadoras (FAGUNDES et al., 2014).

No caso específico da Educação Infantil, Cerisara (1996) já destacava que as profissionais que trabalham com crianças pequenas são pensadas pelo senso comum (contudo, não exclusivamente por ele), a partir da forma como as profissões se construíram historicamente, em que feminino traz consigo o papel do trabalho doméstico e da naturalização das funções maternas com relação à criança. Agregada a essa questão há a tensão histórica entre assistência e educação (MONTENEGRO, 2005; LUZ, 2006), que ronda até os dias atuais as práticas da Educação Infantil, provocando a hierarquização das 


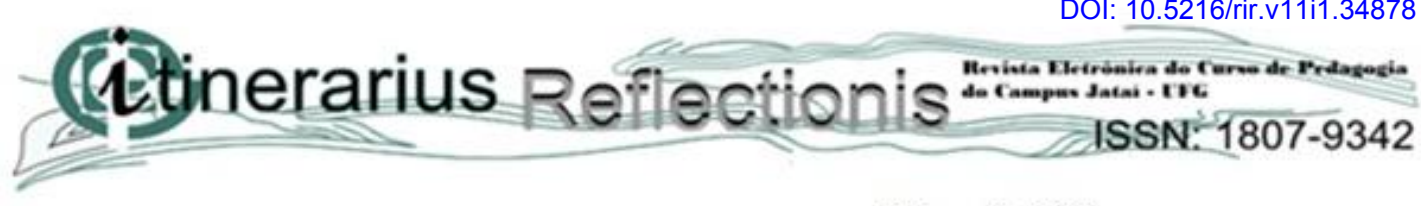

v.11, n. 1,2015

tarefas, a cisão na atribuição dos fazeres e quase unanimemente a não efetivação do cuidar e educar indissociados, como propõem as Diretrizes Curriculares Nacionais para a Educação Infantil (BRASIL, 2010).

Sobre esse ponto, Oliveira-Formosinho (2002, p. 43-44) assinala que

[...] o papel dos professores das crianças pequenas é, em muitos aspectos, similar ao papel dos outros professores, mas é diferente em muitos outros. Esses aspectos diferenciadores configuram uma profissionalidade específica do trabalho das educadoras de infância. Os próprios atores envolvidos na educação de infância têm sentimentos mistos no que se refere à questão de serem iguais ou diferentes dos outros professores, nomeadamente dos outros professores do ensino primário.

Nesse sentido, Angotti (2006, p. 19), afirma que "a profissionalidade dos educadores infantis deve ser fundamentada na efetivação de um cuidar que promova a educação, e de uma educação que não deixe de cuidar da criança, e de atendê-la em suas necessidades e exigências essenciais desde a sua mais tenra idade”.

Considerando os pressupostos explicitados (ainda que brevemente) é que se reafirma a importância de investigar a imagem que os estudantes em processo de formação inicial detêm do que é ser professor na/da Educação Infantil.

\section{SER PROFESSOR NA EDUCAÇÃO INFANTIL É...}

Conforme anunciado, a discussão ora apresentada se configura num substrato de uma pesquisa longitudinal, em andamento desde o ano de 2011. A investigação, de abordagem qualitativa, tem como proposta acompanhar estudantes matriculados em Cursos de Pedagogia, ao longo de todo o processo de formação inicial para a docência, em distintas instituições públicas de ensino superior, com vistas à compreensão de como se dá a evolução da aprendizagem profissional. Os sujeitos são alunos e professores dos Cursos de Pedagogia da Faculdade de Ciências e Tecnologia da Universidade Estadual Paulista "Júlio de Mesquita Filho", Campus de Presidente Prudente (FCT/UNESP), e da Universidade Federal de Mato Grosso do Sul - Campus de Corumbá (CPAN/UFMS). 


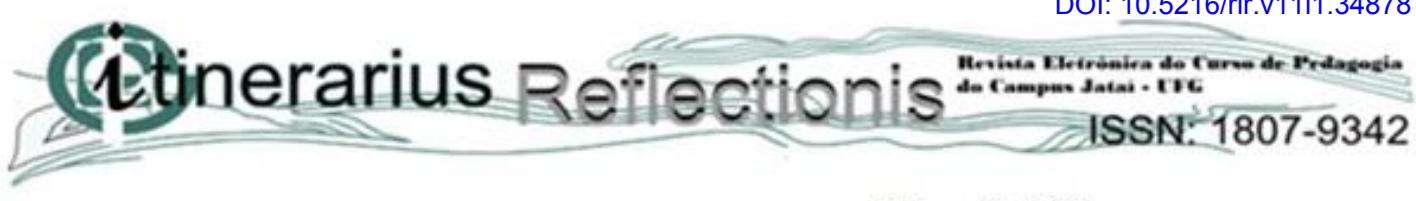

v.11, n. 1,2015

Em seu desenvolvimento, o estudo já passou por três momentos de coleta de dados. O primeiro se deu no início do ano letivo de 2011, quando os estudantes que haviam recémingressado no curso responderam a um questionário misto, composto por 40 questões. Em 2012, segunda fase da pesquisa, um novo questionário foi utilizado, também misto, porém respondido pelos formadores (professores que atuavam nos Cursos de Pedagogia, na época); e, na terceira fase, ocorrida em 2013, os estudantes responderam a outro questionário misto, desta vez composto por 21 questões. Importante assinalar que a última coleta aconteceu no final do ano letivo de 2014, todavia, o trabalho de sistematização e análise dos dados ainda não foi finalizado.

Assim, nos limites deste texto, tendo em vista a intenção de discutir a imagem que os estudantes em processo de formação inicial detêm sobre o que é ser professor, serão expostos dados referentes às coletas feitas em 2011 e 2013, mais especificamente das questões "Ser professor(a) é...", respondida pelos estudantes no ano de 2011, e "Ser professor(a) da Educação Infantil é...”, respondida em 2013.

No ano de 2011, tínhamos um total de 109 sujeitos, sendo 77 da FCT/UNESP ${ }^{4}$ e 32 do CPAN/UFMS ${ }^{5}$, cujo perfil, em ambos os grupos, é de uma composição de cerca de $50 \%$ na faixa etária entre 17 e 20 anos (maior percentual) e do sexo feminino (num percentual médio de 85\%) (FAGUNDES et al., 2014).

A propósito das respostas oferecidas sobre ser professor, cabe destacar que, na análise, elas não foram consideradas excludentes, de sorte que chegamos a um total superior ao número de respondentes. Entre os ingressantes do CPAN/UFMS, percebeu-se uma dispersão muito grande, sendo que a variedade de ideias girou em torno de mediador, formador de opinião, transmissor do conhecimento, orientador, amigo, companheiro, paciente, agente de mudança social, gostar do que faz, compromisso/comprometido, responsabilidade, exemplo, prova de resistência, prazeroso e gratificante, num total de 35 respostas. A ideia com maior índice de frequência (28\%) está relacionada à de profissional

\footnotetext{
${ }^{4}$ Identificados no texto como Sujeitos PP (referente a Presidente Prudente).

${ }^{5}$ Identificados no texto como Sujeitos CB (relativo a Corumbá).
} 


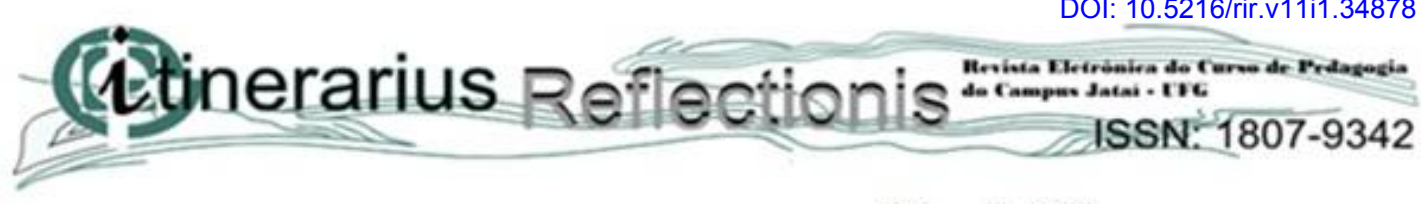

v.11, n. 1,2015

mediador ou transmissor do conhecimento, capaz de orientar seus aprendizes no mundo do conhecimento.

Ter a honra de ensinar as primeiras noções de educação, que irão contribuir para a vida futura dessas crianças. (Sujeito CB_06).

Um formador de opinião, imprescindível para o crescimento e o desenvolvimento social. (Sujeito CB_19).

Fazer mudanças na vida de alguém. (Sujeito CB_27).

É importante destacar que apenas um sujeito desse grupo se refere à profissão de forma negativa, associando-a a prova de resistência.

Por conseguinte, pode-se inferir que, na visão dos ingressantes de Corumbá, ser professor é ser capaz de "ensinar", o que pode ser entendido também como ter domínio do conhecimento. Com frequência pequena, apresenta-se a ideia de responsabilidade na mudança social e características mais pessoais, como ser companheiro e paciente.

No que diz respeito às respostas dos estudantes da FCT/UNESP, num total de 97, notou-se certa discrepância quanto ao grupo anterior, primeiramente no que concerne a uma menor dispersão das ideias, no entanto, com apontamentos próximos, girando em torno de compromisso/comprometimento, orientador, transmissor de conhecimentos, paciente, gostar do que faz, competência, dedicação, doação.

Houve duas ideias que merecem destaque: a de maior índice de indicações (cerca $21 \%$ ), ligada às características de orientador e de profissional comprometido com a mudança dos sujeitos e da sociedade.

[...] alguém de extrema importância para o direcionamento do aluno ao mundo, pois é ele que pode influenciar na construção da autonomia, do modo de se ter moral e ética. (Sujeito PP_01).

Ter uma função muito importante na sociedade, pois é através dele que muitos outros obterão a oportunidade de crescer [...] (Sujeito PP_44).

A segunda maior frequência (17\%) foi o apontamento de gostar do que faz. 


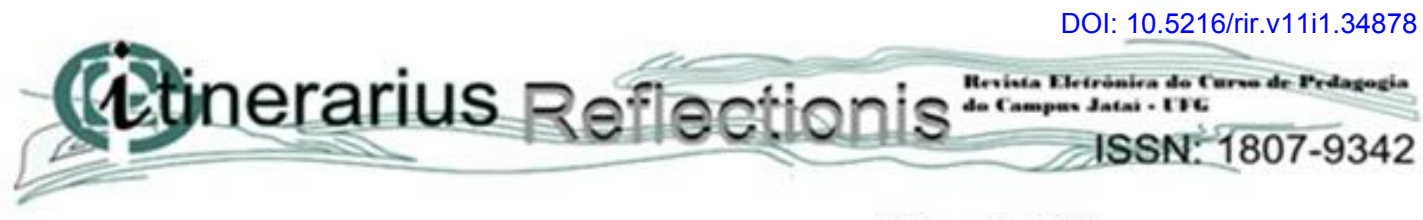

$$
\text { v.11, n. } 1,2015
$$

Gostar do trabalho de ensinar, ter gosto pela profissão que escolheu e sempre buscar novos meios de ensino (Sujeito PP_08).

Gostar de atuar na área [...] e ter como objetivo principal o aprendizado dos alunos (Sujeito PP_52).

Neste grupo, não houve associação da profissão a uma ideia negativa; no entanto, 10 sujeitos apontaram que ser professor é "Se doar a cada dia" (Sujeito PP_17) e outros três sujeitos associaram a profissão à paternidade/maternidade, afirmando que ser professor é também "Ser uma segunda mãe/pai” (Sujeito PP_22).

É certo que, no momento de ingresso no curso, os estudantes ainda não têm clareza e amadurecimento para compreender as várias dimensões que configuram a profissão docente, mas confundi-la com papéis domésticos ou confessionais é algo preocupante, uma vez que, nos dias atuais, não se justifica o entendimento de uma profissão destituída de profissionalidade, principalmente de sujeitos que, em tese, pretendem ingressar nela; por outro lado, deixam claro uma das principais tarefas a serem desempenhadas pelos cursos de formação, quer dizer, desmistificar ideias errôneas acerca da profissão arraigadas no imaginário coletivo; com efeito, embora as percepções sejam reelaboradas por cada indivíduo, essas reelaborações são impulsionadas pelas relações sociais que estabelecemos com diferentes grupos.

Todavia, de modo geral, é possível inferir que os ingressantes de Presidente Prudente entendiam que ser professor é comprometer-se com a profissão e com a tarefa de mudar os sujeitos de sua ação e o entorno, bem como identificar-se/gostar do que se faz.

Cabe, em consequência, apontar que, apesar de haver diferença nas características enfatizadas do que é ser professor, os ingressantes dos dois grupos, com algumas exceções para o grupo de Presidente Prudente, tinham uma percepção muito próxima do que é considerado desejável, pois se adota como pressuposto que,

[q]uando falamos de "ser professor", referimo-nos a uma profissão e a associamos ao conjunto de atividades que este ou aquele trabalhador exerce na maior parte de seu tempo [...]

Podemos dizer então, que professores constituem um grupo permanente e duradouro tendo como papel social fundamental a transmissão do conhecimento 


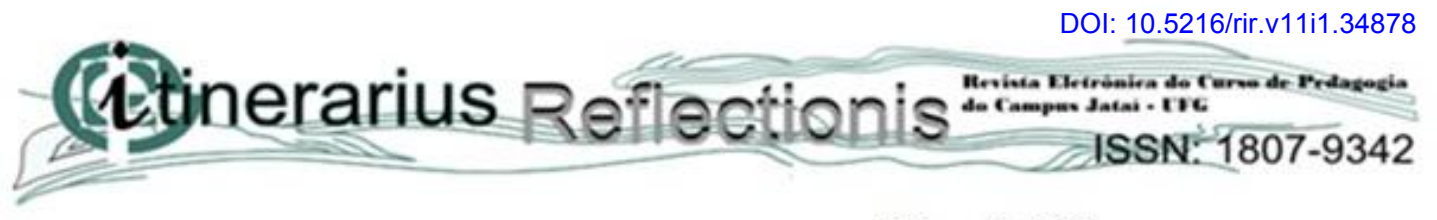

$$
\text { v.11, n. } 1,2015
$$

historicamente acumulado pelas gerações anteriores bem como assegurar a perpetuação de determinadas regras da vida social. (RODRIGUES; GOMES, 2013, p. 27, grifo dos autores).

Por isso, diante desses pressupostos, no ano de 2013, o questionamento acerca do que é ser professor foi lançado de forma mais específica, sugerindo que os estudantes, agora já no $6^{\circ}$ semestre do curso, discorressem sobre sua percepção da profissão localizada em níveis diferentes. Devido à evasão, o número total de sujeitos diminuiu cerca de 30\%, perfazendo no ano letivo de 2013 um total de 78, sendo eles 59 da FCT/UNESP e 19 estudantes do CPAN/UFMS.

Assim, no que diz respeito à questão "Ser professor(a) da Educação Infantil é...", no tratamento dos dados, organizamos as respostas dos estudantes, sem considerá-las excludentes, em quatro grupos: 1- respostas que indicam características pessoais; 2- as que apontam uma identificação pessoal com a profissão; 3- as que remetem às tarefas a serem assumidas; 4- as que ressaltam os conhecimentos necessários ao exercício da profissão.

A propósito das respostas oferecidas pelos estudantes do CPAN/UFMS (num total de 29), a maior frequência de indicação (45\%) está no grupo que indica os conhecimentos necessários ao exercício da profissão docente junto a criança pequena, tais como: perceber a criança como sujeito de direitos, sujeito ativo e ser capaz; considerar a criança como centro do processo; organizar atividades adequadas as características infantis; ser mediador do conhecimento e ser observador (que igualmente poderia ser tomada como uma característica pessoal).

A segunda maior frequência $(42 \%)$ inclui respostas que se referem às tarefas e posturas que devem ser assumidas na prática pedagógica junto às crianças: preparar para a vida; ajudar a criança a evoluir; cuidar e educar; promover o bem-estar; e, estar em constante aprendizagem.

Saber logo de cara o conceito de criança, infância e vê-los como sujeitos de direitos e deveres assim como qualquer um de nós. (Sujeito CB_02). 


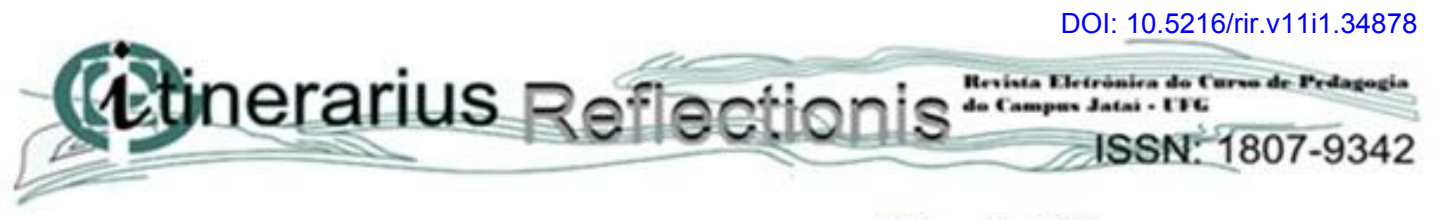

$$
\text { v.11, n. } 1,2015
$$

Ter a responsabilidade e a consciência de que as primeiras noções sobre o mundo e sobre a própria criança, devem partir de uma boa prática pedagógica. (Sujeito CB_10).

Promover o bem estar dentro da sala de aula, através do diálogo, das brincadeiras. [...] (Sujeito CB_11).

Ter a criança como centro em todo o tempo e respeitar as suas peculiaridades e especificidades. (Sujeito CB_15).

[...] enxergar a criança como um ser capaz, produtor de história, um sujeito completo. (Sujeito CB_18).

É importante destacar que não houve nenhum não respondente; somente dois estudantes ofereceram respostas que mostram certa não identificação pessoal com a profissão, ao afirmar que ela é um desafio; com relação a respostas que indicam características pessoais, somente um sujeito faz referência a ser observador, que também pode ser considerada uma das tarefas a serem assumidas no cotidiano da Educação Infantil, dada sua já discutida especificidade.

Tais dados permitem afirmar que os acadêmicos do CPAN/UFMS detêm uma percepção bastante satisfatória e muito próxima do desejável acerca do que é ser professor na Educação Infantil, com respostas que se aproximam dos meandros da necessária profissionalidade dos educadores infantis.

Sobre as respostas oferecidas pelos estudantes da FCT/UNESP (no total de 91), houve discrepâncias entre os grupos. Entre esses estudantes, observou-se certa dispersão nas respostas e a maior frequência (27\%) são das que se referem às tarefas e posturas a serem assumidas na prática pedagógica junto às crianças: promover boa formação; ajudar a criança a evoluir; cuidar e educar; ensinar de forma lúdica; promover o bem estar; e, estar em constante aprendizagem.

Ser um profissional que cuida e educa, contribui para o desenvolvimento emocional, cognitivo e motor da criança [...] (Sujeito PP_33).

Ter uma função muito importante na sociedade, pois é através dele que muitos outros obterão a oportunidade de crescer [...] (Sujeito PP_44).

[...] fazer um trabalho que vise o bem estar da criança. (Sujeito PP_13). 


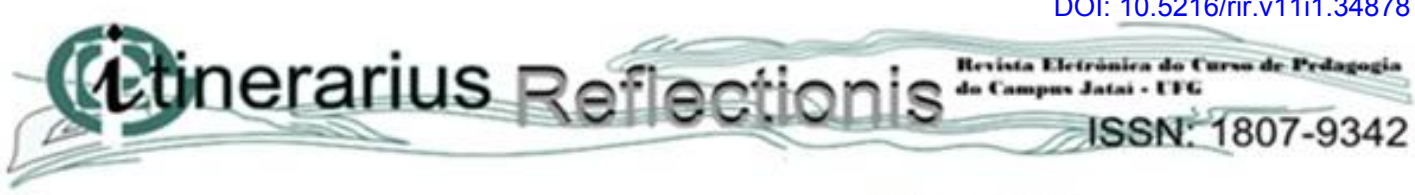

v.11, n. 1,2015

A segunda maior frequência $(20 \%)$ diz respeito às respostas que indicam características pessoais: carinhoso, paciente, atencioso, amoroso, amigo, sensível, dedicado e responsável.

Ser atencioso, amoroso, passar segurança para criança, buscar a melhor maneira de interagir com a criança. (Sujeito PP_20).

Ser um exemplo de paciência, de carinho e saber educar com amor. (Sujeito PP_44).

Em seguida, com $17 \%$ de frequência, estão as respostas que apontam os conhecimentos necessários ao exercício da profissão docente junto à criança pequena, tais como: compreender a criança; valorizar e a infância; perceber a criança como sujeito ativo; entender sobre desenvolvimento infantil; saber formas adequadas de ensino; e ser mediador do conhecimento.

Conhecer e participar ativamente do crescimento do aluno. (Sujeito PP_10).

Ser alguém bem preparado, comprometido, responsável e um importante mediador [...] (Sujeito PP_23).

Com frequência de 9\%, aparecem as respostas as quais denotam uma identificação que pode ser considerada negativa com respeito à profissão, ao se referirem a ela como desafio e desgastante. Nesse grupo, diferentemente do anterior, há respostas que revelam uma identificação positiva com a profissão (com percentual de 7\%), sendo mencionadas as palavras: maravilhoso, gratificante, satisfatório, conquista e profissão bonita.

Conforme já apontado, nesse grupo, surgem respostas que não apareceram no grupo do CPAN/UFMS e não puderam ser enquadradas na organização proposta inicial dos dados: com índice de 7\%, há a indicação de que ser professor da Educação Infantil é gostar do que faz. Esta é uma questão que poderia ser enquadrada nas categorias identificação com a profissão ou características pessoais, mas como não foi levantada pelos sujeitos do outro grupo, optei por mantê-la em separado a fim de permitir uma análise com mais rigor. 


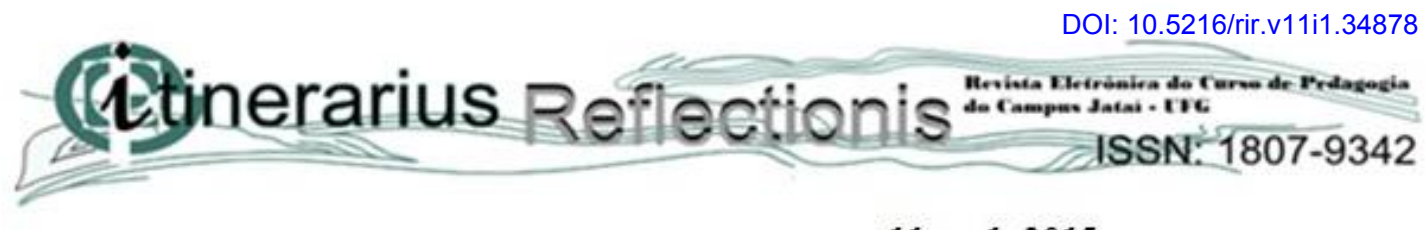

$$
\text { v.11, n. } 1,2015
$$

Ainda nesse grupo, há quatro respostas que denunciam a desvalorização da profissão, como, por exemplo, a do Sujeito PP_05: "Trabalhar infelizmente muitas vezes sem a devida estrutura e o devido apoio [...]"; duas que afirmam que é "Preparar para os anos seguintes" (Sujeito PP_50); e uma que afirma que é "Ser mãe e professora juntas" (Sujeito PP_49). Há ainda três estudantes que não responderam.

Os dados do grupo de estudantes da FCT/UNESP nos permitem concluir que a maioria deles não detém uma percepção desejável acerca do que é ser professor, na Educação Infantil. Há a impressão de que a visão a respeito da atuação docente, no citado nível de ensino, por parte de uma significativa parcela dos acadêmicos desse curso, ainda é romantizada e marcada pelo ideário do senso comum, no qual características pessoais, como amoroso e paciente, são básicas para ser professor de crianças pequenas. Não que elas não sejam, mas elas devem vir acompanhadas de outras tão ou mais importantes e que caracterizam de forma mais respeitosa a profissionalidade para esse nível.

\title{
4 À GUISA DE CONCLUSÃO
}

\author{
O inesperado surpreende-nos. \\ É que nos instalamos de maneira segura \\ Em nossas teorias e idéias, e estas não têm \\ estruturas para acolher o novo. \\ Entretanto, o novo brota sem parar. \\ (Edgar Morin) ${ }^{6}$
}

A provocativa epígrafe alerta para a iminência do novo e o quanto as velhas ideias podem servir de barreira para esse novo... Entre outras possibilidades, usá-la-ei neste momento como analogia para a força das ideias advindas do senso comum... O quanto elas podem ser impeditivas de novos horizontes; e, trazendo para a discussão em pauta, para novas práticas pedagógicas na Educação Infantil... Sim, porque as ideias equivocadas fortemente arraigadas no ideário dos professores advêm dessa fonte, a qual os cursos de formação inicial não tem conseguido enfrentar com sucesso.

\footnotetext{
${ }^{6}$ MORIN, E. Os sete saberes necessários à educação do futuro. 2. ed. São Paulo: Cortez; Brasília, DF: Unesco, 2000.
} 


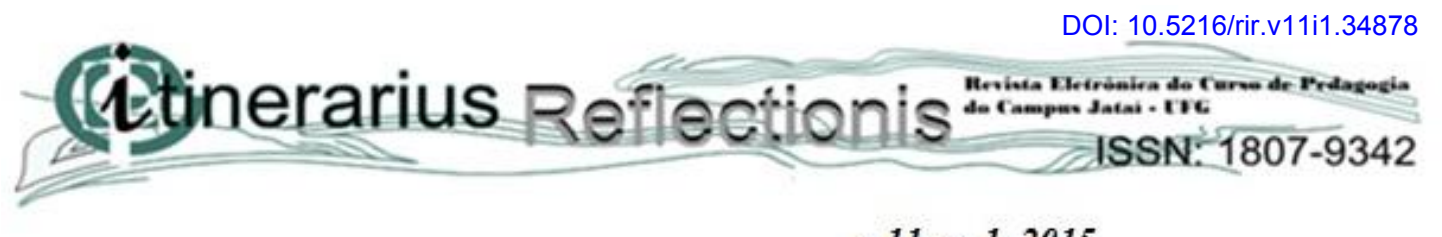

$$
\text { v.11, n. } 1,2015
$$

A relação entre senso comum e mudança se evidencia em alguns dos dados examinados neste texto. O grupo de respostas dos estudantes da FCT/UNESP sugere a pequena mudança que o curso provocou, no ideário de seus acadêmicos do Curso de Pedagogia. No caso dos estudantes do CPAN/UFMS, faz-se necessário ter cautela em afirmar que a formação inicial possa ter provocado mudanças na percepção desses estudantes, uma vez que, no início da investigação, o questionamento não foi tão específico (relacionado diretamente à docência na Educação Infantil), sendo necessário aguardar a análise dos dados finais.

A questão da formação das educadoras infantis tem ocupado o espaço de amplos e diversos debates, contudo, ainda se configura em "nó górdio" que os cursos de formação precisam procurar formas de desatar...

Concluo, por conseguinte, que a perspectiva formativa aqui defendida destaca a importância e a necessidade urgente da criação de espaços/oportunidades para os professores questionarem suas crenças e práticas institucionais, localizarem seus pontos de resistência a mudanças, tendo como premissa que os profissionais docentes são produtores de conhecimento e não apenas seus disseminadores.

\section{REFERÊNCIAS}

ANGOTTI, M. Educação Infantil: para que, para quem e por quê. In: (Org.).

Educação Infantil: para que, para quem e por quê? Campinas: Alínea, 2006. p. 15-32.

BRASIL. Constituição (1988). Constituição da República Federativa do Brasil: promulgada em 5 de outubro de 1988. Disponível em: http://www.planalto.gov.br/ccivil_03/constituicao/constituicao.htm. Acesso em: 18 fev. 2009.

BRASIL. Lei no. 9.394, de 20 de dezembro de 1996. Estabelece as diretrizes e bases da educação nacional. Disponível em: http://www.planalto.gov.br/ccivil_03/leis/19394.htm. Acesso em: 18 fev. 2009.

BRASIL. Conselho Nacional de Educação. Resolução CNE/CP n⿳ 1/2006. Institui Diretrizes Curriculares Nacionais para o Curso de Graduação em Pedagogia, licenciatura. 


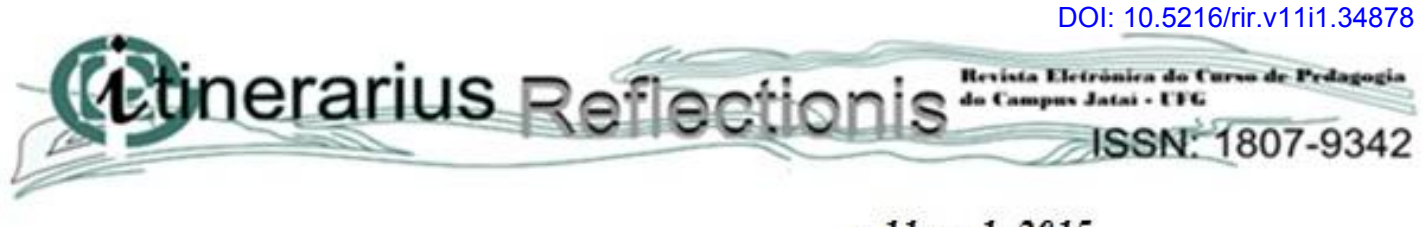

$$
\text { v.11, n. } 1,2015
$$

Disponível em: http://portal.mec.gov.br/cne/arquivos/pdf/rcp01_06.pdf. Acesso em: 15 ago. 2014.

CERISARA, A. B. Professoras de Educação Infantil: entre o feminino e o profissional. 1996. Tese (Doutorado em Educação) - Faculdade de Educação - USP, São Paulo, 1996.

FAGUNDES, S. B. et al. Expectativas de estudantes sobre a profissão docente. In: CONGRESSO NACIONAL DE FORMAÇÃO DE PROFESSORES, III; Congresso Estadual Paulista sobre Formação, XII. Anais... Águas de Lindóia: UNESP, 2014.

GOMES, M. de O. Formação de professores na Educação Infantil. São Paulo: Cortez, 2009.

LEITE FILHO, A. Rumos da Educação Infantil no Brasil. Revista Teias, Rio de Janeiro, ano 6, n. 11-12, jan./dez. 2005.

LUZ, I. R. Educação infantil: direito reconhecido ou esquecido? Revista Linhas Críticas, v. 12, n. 22, p. 41-58, jan./jun. 2006.

MONTENEGRO, T. Educação infantil: a dimensão moral da função de educar. Psicologia da Educação - Revista do Programa de Estudos Pós-Graduados em Psicologia da Educação PUC-SP, São Paulo: EDUC, n. 20, p. 77-101, 1º sem. 2005.

OLIVEIRA-FORMOSINHO, J. O desenvolvimento profissional das educadoras de infância: entre os saberes e os afetos, entre a sala e o mundo. In: OLIVEIRAFORMOSINHO, J.; KISHIMOTO, T. M. (Org.). Formação em contexto: uma estratégia de integração. São Paulo: Pioneira Thomson Learning, 2002. p. 41-88.

OSTETTO, L. E. Articular saberes, qualificar práticas: contribuiçõos da universidade à formação dos profissionais de educação infantil. Perspectiva, Florianópolis, v. 15, p. 11-20, jul./dez. 1997. Disponível em:

https://periodicos.ufsc.br/index.php/perspectiva/article/viewFile/10613/10147. Acesso em: 08 fev. 2013.

PASCHOAL, J. D.; MACHADO, M. C. G. A história da educação infantil no Brasil: avanços, retrocessos e desafios dessa modalidade-educacional. Revista. Histedbr, Campinas, n. 33, p.78-95, mar. 2009.

ROCHA, E. A. C. As pesquisas sobre a educação infantil no Brasil: a trajetória na ANPED (1990-1996). Pro-posições, Campinas, v. 10, n. 1 (28), p. 54-74, mar. 1999. 


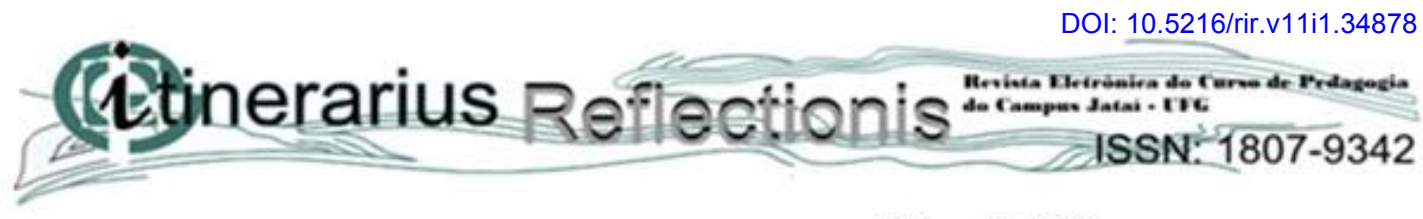

$$
\text { v.11, n. } 1,2015
$$

RODRIGUES, S. A. Reflexões sobre a organização de práticas educativas no contexto da Educação Infantil. Nuances: estudos sobre Educação, Ano XIX, n. 25, v. 1, p. 183-199, jan./abr. 2013.

Expressividade e emoções na primeira infância: um estudo sobre a interação criança-criança na perspectiva walloniana. 2008. 110 f. Dissertação (Mestrado em Educação) - Faculdade de Ciências e Tecnologia, Universidade Estadual Paulista, Presidente Prudente, 2008.

; GOMES, A. A. Profissão professor: como estudantes em processo de formação inicial percebem o bom profissional. In: ENCONTRO DE POLÍTICAS E PRÁTICAS DE FORMAÇÃO DE PROFESSORES, V. Anais eletrônicos. Campo Grande: UCDB, p. 2538, 2013.

SANTOS, C. G. L. dos; FURTADO, E. R. Professor na Educação Infantil: formação, identidade, e saberes. In: SEMINÁRIO EDUCAÇÃO, 2013. Anais... Cuiabá: UFMT, 2013.

SILVEIRA, G. L.; FREIRE, D. Significações acerca da profissionalidade docente na Educação Infantil. In: SEMINÁRIO EDUCAÇÃO 2013. Anais... Cuiabá: UFMT, 2013. 